Article

\title{
Impact of Phase Structure on Piezoelectric Properties of Textured Lead-Free Ceramics
}

\author{
Xiaoyi Gao ${ }^{1,2,3}$, Nannan Dong $\left.{ }^{1}{ }^{(}\right)$, Fangquan Xia ${ }^{4}$, Qinghu Guo ${ }^{1}$, Hua Hao ${ }^{1} *$, Hanxing Liu ${ }^{3}$ \\ and Shujun Zhang ${ }^{2, *}$ \\ 1 State Key Lab Silicate Materials for Architecture, Center for Smart Materials and Device Integration, School \\ of Materials Science and Engineering, Wuhan University of Technology, Wuhan 430070, China; \\ xygao@whut.edu.cn (X.G.); 18271861079@whut.edu.cn (N.D.); guoqinghu126@foxmail.com (Q.G.) \\ 2 Institute for Superconducting and Electronic Materials, Australian Institute of Innovative Materials, \\ University of Wollongong, Wollongong, NSW 2500, Australia \\ 3 State Key Laboratory of Advanced Technology for Materials Synthesis and Processing, International School \\ of Materials Science and Engineering, Wuhan University of Technology, Wuhan 430070, China; \\ lhxhp@whut.edu.cn \\ 4 School of Chemistry and Chemical Engineering, University of Jinan, Jinan 250022, China; \\ chm_xiafq@ujn.edu.cn \\ * Correspondence: haohua@whut.edu.cn (H.H.); shujun@uow.edu.au (S.Z.)
}

Received: 6 April 2020; Accepted: 2 May 2020; Published: 3 May 2020

check for updates

\begin{abstract}
The impact of phase structure on piezoelectric performances of $<001>$ textured $\mathrm{Na}_{0.5} \mathrm{Bi}_{0.5} \mathrm{TiO}_{3}$ (NBT) based lead-free ceramics was studied, including $0.88 \mathrm{NBT}-0.08 \mathrm{~K}_{0.5} \mathrm{Bi}_{0.5} \mathrm{TiO}_{3}-0.04 \mathrm{BaTiO}_{3}$ (88NBT) with morphotropic phase boundary (MPB) composition and $0.90 \mathrm{NBT}-0.07 \mathrm{~K}_{0.5} \mathrm{Bi}_{0.5} \mathrm{TiO}_{3}-0.03 \mathrm{BaTiO}_{3}$ (90NBT) with rhombohedral phase. Both textured ceramics exhibit a high Lotgering factor, being on the order of $\mathrm{f} \sim 96 \%$. The piezoelectric coefficients of the textured $88 \mathrm{NBT}$ and $90 \mathrm{NBT}$ ceramics are increased by $20 \%$ and $60 \%$, respectively, comparing to their randomly oriented ceramics. The piezoelectric enhancement of $90 \mathrm{NBT}$ textured ceramic is three times higher than $88 \mathrm{NBT}$, revealing the phase structure plays a significant role in enhancing the piezoelectric performances of textured ceramics. Of particular significance is that the 90NBT textured ceramic exhibits almost hysteresis-free strain behavior. The enhanced piezoelectric property with minimal strain hysteresis is attributed to the $<001>$ poled rhombohedral engineered domain configuration.
\end{abstract}

Keywords: textured ceramics; phase structure; rayleigh analysis; strain behavior

\section{Introduction}

In recent years, lead-free piezoelectric materials based on $\mathrm{Na}_{0.5} \mathrm{Bi}_{0.5} \mathrm{TiO}_{3}$ (NBT) have attracted extensive attention, which is considered to be a potential candidate due to their good ferroelectric and piezoelectric properties, with high Curie temperature $\mathrm{T}_{\mathrm{C}}$ of $320^{\circ} \mathrm{C}$ and large remnant polarization $P_{r}$ value of $38 \mu \mathrm{C} / \mathrm{cm}^{2}$ [1]. However, there is still a need to enhance the properties of NBT-based ceramics before they can replace lead-based materials. Improvements in piezoelectric properties have been studied in NBT-based solid solutions with morphotropic phase boundary (MPB) [2-8] such as $\mathrm{Na}_{0.5} \mathrm{Bi}_{0.5} \mathrm{TiO}_{3}-\mathrm{SrTiO}_{3}$ (NBT-ST), $\mathrm{Na}_{0.5} \mathrm{Bi}_{0.5} \mathrm{TiO}_{3}-\mathrm{BaTiO}_{3}(\mathrm{NBT}-\mathrm{BT}), \mathrm{Na}_{0.5} \mathrm{Bi}_{0.5} \mathrm{TiO}_{3}-\mathrm{K}_{0.5} \mathrm{Bi}_{0.5} \mathrm{TiO}_{3}-\mathrm{BaTiO}_{3}$ (NBT-KBT-BT), and $\mathrm{Na}_{0.5} \mathrm{Bi}_{0.5} \mathrm{TiO}_{3}-\mathrm{K}_{0.5} \mathrm{Bi}_{0.5} \mathrm{TiO}_{3}-\mathrm{SrTiO}_{3}$ (NBT-KBT-ST), but with limited success. It is difficult to increase the piezoelectric performances of NBT-based binary and ternary polycrystalline ceramics further by only composition tuning.

Texturing is a promising approach to enhance the piezoelectric performances of ferroelectric ceramics via controlling the microstructure without drastically changing the 
composition [9-11] taking advantage of grain alignment along ab specific crystallographic direction, thus showing unique anisotropic behavior, being analogous to domain engineering reported in ferroelectric single crystals [12-15]. More studies have been done on texturing of lead-free ceramics in recent years [16-21] such as <001>-textured NBT-BT [22], NBT-KBT [23], NBT-BT-KNN [24], $\mathrm{Ba}\left(\mathrm{Zr}_{0.2} \mathrm{Ti}_{0.8}\right) \mathrm{O}_{3}-\left(\mathrm{Ba}_{0.7} \mathrm{Ca}_{0.3}\right) \mathrm{TiO}_{3}$ (BZT-BCT) [21], $\left(\mathrm{K}_{0.5} \mathrm{Na}_{0.5}\right)\left(\mathrm{Nb}_{0.965} \mathrm{Sb}_{0.035}\right) \mathrm{O}_{3}-\mathrm{CaZrO}_{3}-\left(\mathrm{Bi}_{0.5} \mathrm{~K}_{0.5}\right) \mathrm{HfO}_{3}$ [16] and $\mathrm{Bi}_{0.5} \mathrm{Na}_{0.5} \mathrm{TiO}_{3}-\mathrm{BaTiO}_{3}-\mathrm{AgNbO}_{3}$ (NBT-BT-AN) [19] ceramics, etc. The impact of different seed templates on ferroelectric and piezoelectric properties of the textured ceramics has been extensively studied; however, the investigation of the phase structure impact on textured ceramics is rare. It is known that the phase structure, such as rhombohedral/tetragonal phases or the coexistence of them, plays an important role in dominating the piezoelectric properties of ceramics [5]. Meanwhile, different domain engineering configurations, i.e., poling along different crystallographic orientations in single crystals with different phases, were reported to impact the piezoelectric and dielectric properties of crystals significantly [12]. Thus, it is desired to explore the impact of phase structure on the properties of textured ceramics, especially in $<001>$-textured ceramics.

In this work, $0.88 \mathrm{Na}_{0.5} \mathrm{Bi}_{0.5} \mathrm{TiO}_{3}-0.08 \mathrm{~K}_{0.5} \mathrm{Bi}_{0.5} \mathrm{TiO}_{3}-0.04 \mathrm{BaTiO}_{3}(88 \mathrm{NBT})$ with MPB composition and $0.90 \mathrm{Na}_{0.5} \mathrm{Bi}_{0.5} \mathrm{TiO}_{3}-0.07 \mathrm{~K}_{0.5} \mathrm{Bi}_{0.5} \mathrm{TiO}_{3}-0.03 \mathrm{BaTiO}_{3}(90 \mathrm{NBT})$ with rhombohedral (R) phase were selected as matrix, while $\mathrm{NaNbO}_{3}(\mathrm{NN})$ was chosen as template. The intrinsic and extrinsic contributions to the piezoelectric response of ceramics were studied by Rayleigh analysis. Moreover, in this paper, the impact of phase structure on piezoelectric properties of $<001>$-textured ceramics and randomly oriented ceramics is discussed in detail.

\section{Materials and Methods}

The randomly oriented $88 \mathrm{NBT}$ and $90 \mathrm{NBT}$ ceramics were prepared at $1150{ }^{\circ} \mathrm{C}$ for $3 \mathrm{~h}$ by solid-state reaction method. The $\mathrm{Na}_{2} \mathrm{CO}_{3}$ (Aladdin Industrial Corportation, Shanghai, China, $99 \%$ ), $\mathrm{BaCO}_{3}$ (Aladdin Industrial Corportation, Shanghai, China, 99\%), $\mathrm{K}_{2} \mathrm{CO}_{3}$ (Aladdin Industrial Corportation, Shanghai, China, 99\%), $\mathrm{TiO}_{2}$ (Sinopharm Chemical Reagent Co. Ltd, Shanghai, China, 99\%) and $\mathrm{Bi}_{2} \mathrm{O}_{3}$ (Sinopharm Chemical Reagent Co. Ltd, Shanghai, China, 99.9\%) were used as raw materials. The $<001>$-textured $88 \mathrm{NBT}$ and $90 \mathrm{NBT}$ ceramics were fabricated at $1165{ }^{\circ} \mathrm{C}$ for $10 \mathrm{~h}$ via the template grain growth method (TGG) with $4 \mathrm{wt} \%$ platelet NN as templates. Plate-like NN templates with a length of $\sim 10 \mu \mathrm{m}$ were obtained via topochemical conversion [25]. Detailed information on the TGG method and sintering process has been represented elsewhere [26].

The phase structure and the Lotgering factor were determined by X-ray diffraction (XRD) (PANalytical X' Pert PRO, Holland, Netherlands). The Lotgering factor of $<001>$ textured ceramics was calculated with $2 \theta$ over a range of $20-60^{\circ} \mathrm{C}$ by Lotgering method [27]. The microstructure of samples was examined by a scanning electron microscopy (SEM) (JSM-7001F, JEOL, Tokyo, Japan). The samples were placed in a silicone oil bath and polarized for $15 \mathrm{~min}$ at room temperature under a dc electric field of $50 \mathrm{kV} / \mathrm{cm}$, for measuring the dielectric and piezoelectric properties. The direct piezoelectric coefficient $\left(\mathrm{d}_{33}\right)$ was determined by a $\mathrm{d}_{33}$-meter (ZJ-3A, Jiangsu, China) while the effective piezoelectric coefficient $\left(\mathrm{d}_{33}{ }^{*}\right)$ was calculated from the strain-electric field curves. The strain-electric field (S-E) curves were tested at $10 \mathrm{~Hz}$ by a TF Analyzer 2000 piezo-measurement system (aixACCT Systems, Aachen, Germany) with a high-voltage power supply (TREK 610E, NY, USA). For Rayleigh analysis, the maximum electric field with $10 \mathrm{~Hz}$ frequency was about half of the coercive field $\left(\mathrm{E}_{\mathrm{C}}\right)$ of NBT-based ceramics, being on the order of $20 \mathrm{kV} / \mathrm{cm}$. The large signal piezoelectric coefficient $\mathrm{d}_{33}{ }^{*}$ was obtained from the unipolar strain curves measured at $70 \mathrm{kV} / \mathrm{cm}$.

\section{Results and Discussion}

XRD patterns of 88NBT and 90NBT ceramics are shown in Figure 1A. All samples present the perovskite structure with no secondary impurity phase. The $(003) /(021)$ and $(002) /(200)$ peaks appear at $2 \theta$ of $40^{\circ}$ and $46.5^{\circ}$ in randomly oriented 88NBT ceramic, respectively, demonstrating an MPB region 
with the coexistence of rhombohedral-tetragonal phases, which is in good agreement with the results reported earlier [28]. For the randomly oriented 90NBT ceramic, on the contrary, the $(003) /(021)$ and single peak of (200) can be observed at around $40^{\circ}$ and $46.5^{\circ}$, respectively, confirming the presence of rhombohedral phases. In all textured ceramics, the intensities of the (200) peaks are higher than other diffraction peaks, demonstrating a strongly preferred grain orientation in the 88NBT and 90NBT textured ceramics along $<001>$ direction. Based on the XRD results, the Lotgering factor (f) of the textured ceramics can be estimated by Lotgering equations [27]. The $f$ values of the $88 \mathrm{NBT}$ and $90 \mathrm{NBT}$ textured ceramics are on the order of $96 \%$. This result indicates that the textured $88 \mathrm{NBT}$ and $90 \mathrm{NBT}$ ceramics possess the same high Lotgering factor.
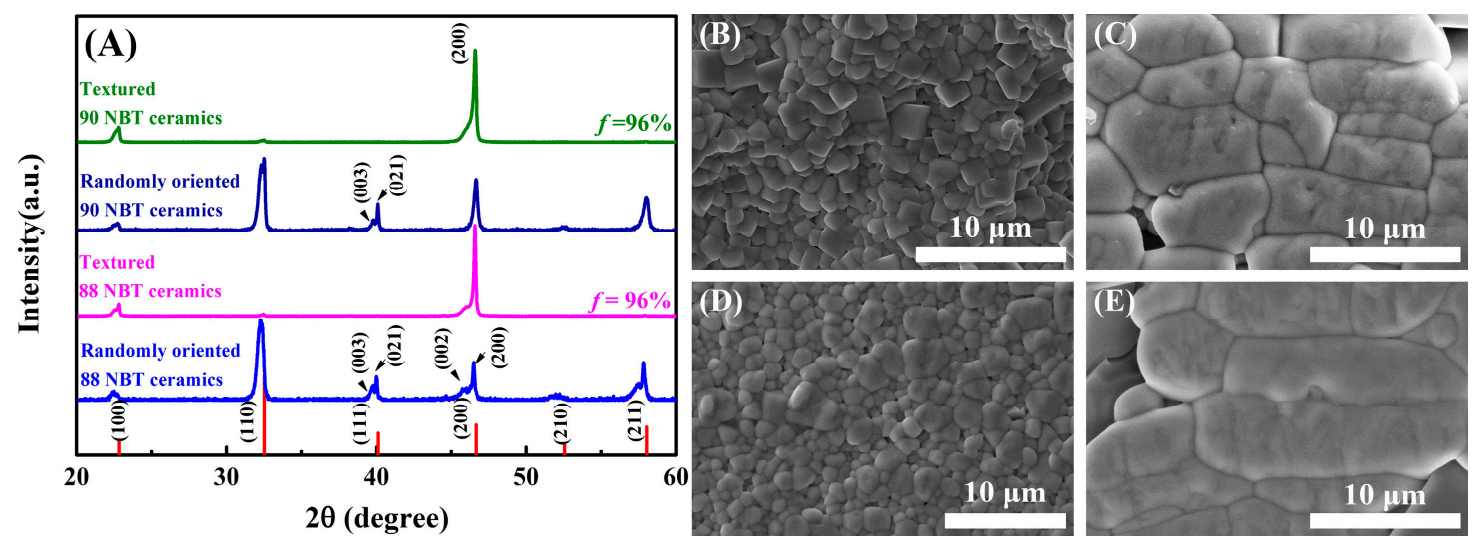

Figure 1. (A) XRD patterns of the randomly oriented ceramics and textured ceramics. SEM images of (B) randomly oriented 88NBT ceramic, (C) textured 88NBT ceramic, (D) randomly oriented 90NBT ceramic, and (E) textured 90NBT ceramic.

Figure 1B-E show the cross-section SEM micrographs of the 88NBT and 90NBT ceramics. As shown in Figure 1B,D, the average grain sizes of the randomly oriented 88NBT and 90NBT ceramics are observed to possess similar values, being on the order of $\sim 1 \mu \mathrm{m}$, suggesting the composition/phase has minimal impact on the grain size of the randomly oriented ceramics. Meanwhile, the $88 \mathrm{NBT}$ and 90NBT textured ceramics are observed to possess the brick-like shaped grains, which is in good agreement with the crystallographic orientation, as demonstrated by XRD patterns shown in Figure 1A, further clarify the strong grain orientation. It is obvious that the textured ceramics have much larger grain size in contrast to the randomly oriented ceramics, being on the order of $\sim 10 \mathrm{um}$.

Figure 2 shows the temperature-dependent of dielectric constant and dielectric loss of poled 88 and 90 NBT ceramics. The maximum temperature $\left(T_{m}\right)$ at which the dielectric constant reached a maximum value is assigned to the Curie temperature. The broad peaks at $T_{m}$ are observed, either on randomly oriented or textured ceramics. Notably, the peaks at $T_{m}$ of textured ceramics are flattened, comparing to the randomly oriented ceramics because of the stress induced by the embedded templates. The depolarization temperature $\left(\mathrm{T}_{\mathrm{d}}\right)$ for textured and randomly oriented ceramics are confirmed by the first inflection point of dielectric loss curves. For 88 NBT ceramics, the $T_{d}$ are about $80^{\circ} \mathrm{C}$, which are below the $\mathrm{T}_{\mathrm{d}}$ of $90 \mathrm{NBT}$ ceramics. The $\mathrm{T}_{\mathrm{d}}$ of textured and randomly oriented ceramics are about 100 and $120^{\circ} \mathrm{C}$, respectively.

To further explore the relationship between phase and piezoelectric response, Rayleigh analysis of NBT-based ceramics was carried out. Under the low electric field, the Rayleigh law can be expressed by the following formulas [29]:

$$
\begin{gathered}
\mathrm{d}\left(\mathrm{E}_{0}\right)=\left(\mathrm{d}_{\text {init }}+\alpha \mathrm{E}_{0}\right) \mathrm{pm} / \mathrm{V} \\
\mathrm{S}(\mathrm{E})=\left(\mathrm{d}_{\text {init }}+\alpha \mathrm{E}_{0}\right) \mathrm{E} \pm \alpha\left(\mathrm{E}_{0}^{2}-\mathrm{E}^{2}\right) / 2
\end{gathered}
$$

where $\mathrm{E}_{0}$ denotes the level of electric-field, $\mathrm{S}(\mathrm{E})$ denotes the ac electric-field-induced strain. In the piezoelectric response, the reversible piezoelectric response, resulting from the intrinsic (lattice) and 
reversible motion of internal interfaces, is described by coefficient $d_{\text {init }}$. The contribution of the latter is relatively small in the ferroelectric materials $[29,30]$. Therefore, in the study, the coefficient $d_{\text {init }}$ is considered to be caused by the intrinsic contribution. The extrinsic contribution to the total piezoelectric response $\alpha \mathrm{E}_{0}$ is arising from the irreversible domain walls motion, where the measured coefficient $\alpha$ represents the Rayleigh parameter. From Rayleigh analysis, the electric field dependent $d_{33}$ is calculated by $\mathrm{d}_{33}=\mathrm{S}_{\mathrm{p}-\mathrm{p}} / 2 \mathrm{E}_{0}$, where the $\mathrm{S}_{\mathrm{p} \text {-p }}$ is peak-to-peak strain. The $\mathrm{d}_{33}$ of the randomly oriented and textured ceramics were plotted as a function of ac electric field $E_{0}$ and given in Figure 3 . The $d_{33}$ had a good linear correlation with $\mathrm{E}_{0}$, indicating the piezoelectric response follows the Rayleigh law. According to Equation (1), $\mathrm{d}_{\text {init }}$ values are on the order of $67,124,72,141 \mathrm{pm} / \mathrm{V}$ for randomly oriented and textured $88 \mathrm{NBT}$ and $90 \mathrm{NBT}$ ceramics, respectively. $\alpha$ are found to be $2.61 \mathrm{~cm} / \mathrm{kV}, 2.36 \mathrm{~cm} / \mathrm{kV}$, $2.06 \mathrm{~cm} / \mathrm{kV}, 1.52 \mathrm{~cm} / \mathrm{kV}$, respectively.
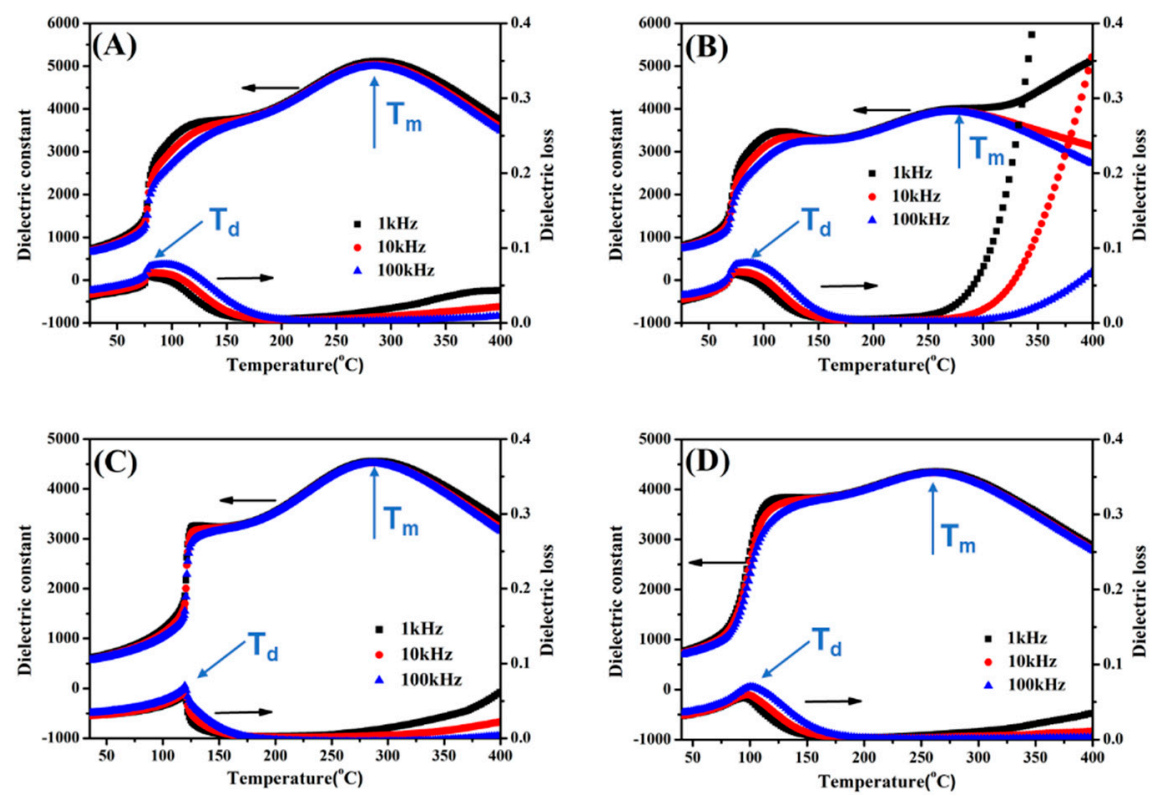

Figure 2. Temperature-dependent of dielectric constant and dielectric loss of (A) 88NBT randomly oriented ceramic, (B) $88 \mathrm{NBT}$ textured ceramic, (C) 90NBT randomly oriented ceramic, and (D) 90NBT textured ceramic.

Based on the Rayleigh analysis, $\alpha \mathrm{E}_{0} /\left(\alpha \mathrm{E}_{0}+\mathrm{d}_{\text {init }}\right)$, the ratios of extrinsic contribution were calculated and given in Figure 4. The ratios of extrinsic contributions for randomly oriented and textured 88NBT and $90 \mathrm{NBT}$ ceramics are found to be on the order of $\sim 43 \%, 27 \%, 37 \%$, and $\sim 18 \%$ at an electric field of $20 \mathrm{kV} / \mathrm{cm}$, respectively. The results indicate that textured 88NBT ceramic possesses a lower extrinsic contribution of $27 \%$ comparing to the randomly oriented $88 \mathrm{NBT}$ ceramic. In ferroelectric materials, it is known that ferroelastic domain-wall motion, is the main factor for extrinsic contribution [31,32]. Thus, in contrast to the randomly oriented ceramics, textured 88NBT ceramic possesses lower ferroelastic domain-wall motion. It can be noted that the extrinsic contribution of ceramics is usually accompanied by strong nonlinearity and large strain hysteresis, according to the results of Rayleigh analysis. Similarly, when the extrinsic contribution is reduced, the corresponding strain hysteresis is expected to reduce. 

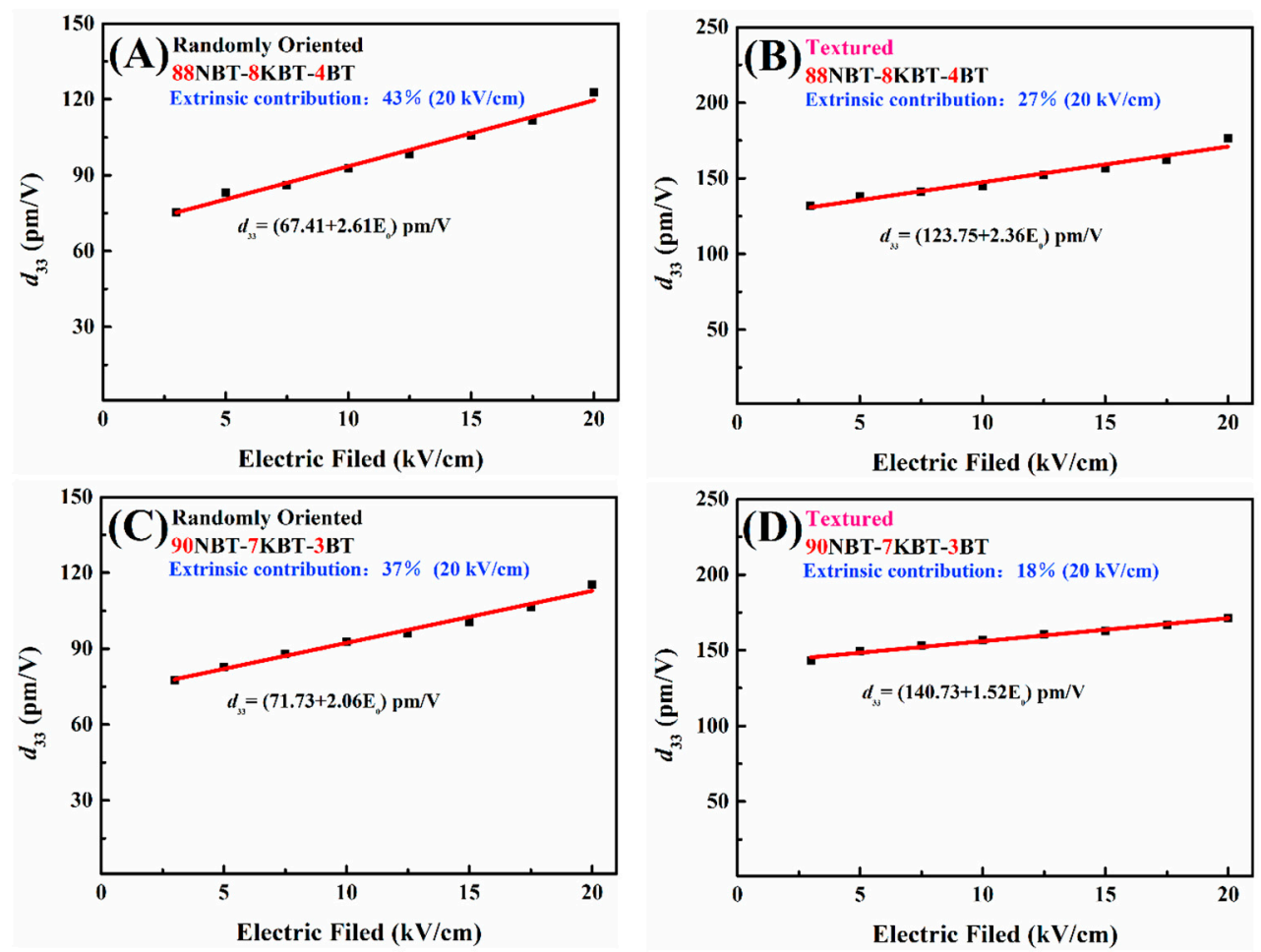

Figure 3. The $\mathrm{d}_{33}$ as a function of ac electric field for (A) randomly oriented $88 \mathrm{NBT}$ ceramic, (B) textured 88 NBT ceramic, (C) randomly oriented 90NBT ceramic, and (D) textured 90NBT ceramic.

(A)

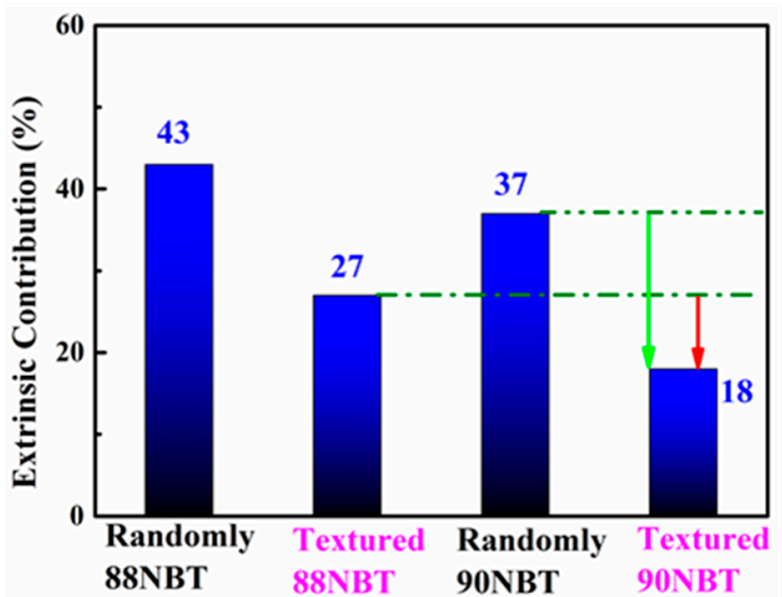

(B)

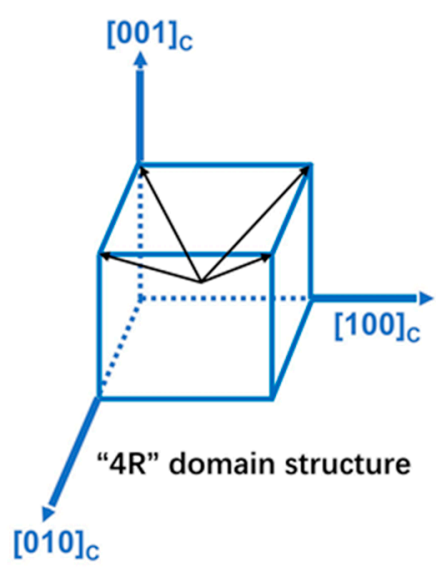

Figure 4. (A) The ratios of extrinsic contribution for randomly oriented 88NBT ceramic, textured 88NBT ceramic, randomly oriented 90NBT ceramic, and textured 90NBT ceramic. (B) The scheme of "4R" domain structure. The black arrow shows the possible domain vector in [001] poled rhombohedral single crystals.

The principle piezoelectric and dielectric properties are listed in Table 1. As shown in Table 1, $\mathrm{d}_{33}$ are 150 and $110 \mathrm{pC} / \mathrm{N}$ for the 88NBT and 90NBT randomly oriented ceramics, respectively, increasing to the value of $\sim 185 \mathrm{pC} / \mathrm{N}$ and $\sim 175 \mathrm{pC} / \mathrm{N}$ for the textured ceramics, respectively, demonstrating $20 \%$ and $60 \%$ enhancements, respectively. This result shows that the piezoelectric properties of $90 \mathrm{NBT}$ textured ceramic have been significantly improved, compared to the 88NBT textured ceramic with MPB composition. The enhanced piezoelectric performance in textured 90NBT ceramic is closely associated with the domain configurations and crystallographic structure. Analogous to $<001>$ oriented single crystals, as shown in Figure 4B, specific domain configuration "4R" (where 4 means the number of 
degenerated polarization directions while $\mathrm{R}$ represents rhombohedral phase) can also be expected to form in $<001>$ textured $90 \mathrm{NBT}$, accounting for the enhanced piezoelectric properties and reduced dielectric loss as compared to its randomly oriented ceramics.

Table 1. The properties of 88NBT ceramics, and 90NBT ceramics.

\begin{tabular}{|c|c|c|c|c|c|c|c|c|c|}
\hline Material & $\begin{array}{l}\text { Phase } \\
\text { Structure }\end{array}$ & $\begin{array}{c}\varepsilon \\
(1 \mathrm{kHz})\end{array}$ & $\begin{array}{l}\tan \delta(a t \\
1 \mathrm{kHz})\end{array}$ & $\begin{array}{c}S_{\mathrm{m}} \\
\text { (at } 70 \mathrm{kV} / \mathrm{cm} \text { ) }\end{array}$ & $\begin{array}{c}\mathrm{d}_{33} \\
(\mathrm{pC} / \mathrm{N})\end{array}$ & $\begin{array}{c}\mathrm{d}_{33} \\
\text { Enhancement }\end{array}$ & $\begin{array}{c}d_{33^{*}} \\
(\mathrm{pm} / \mathrm{V})\end{array}$ & $\begin{array}{c}d_{33^{*}} \\
\text { Enhancement }\end{array}$ & $\mathbf{H}$ \\
\hline $\begin{array}{l}\text { Randomly oriented } \\
\text { 90NBT ceramic }\end{array}$ & $\mathrm{R}$ & 590 & $0.029 \%$ & $0.13 \%$ & 110 & $60 \%$ & 180 & $13 \%$ & $26 \%$ \\
\hline $\begin{array}{l}\text { Textured 90NBT } \\
\text { ceramic }\end{array}$ & $\mathrm{R}$ & 760 & $0.027 \%$ & $0.14 \%$ & 175 & & 205 & & $12 \%$ \\
\hline $\begin{array}{l}\text { Randomly oriented } \\
\text { 88NBT ceramic }\end{array}$ & MPB & 730 & $0.035 \%$ & $0.18 \%$ & 150 & $20 \%$ & 260 & none & $28 \%$ \\
\hline $\begin{array}{l}\text { Textured 88NBT } \\
\text { ceramic }\end{array}$ & MPB & 810 & $0.029 \%$ & $0.18 \%$ & 185 & & 255 & & $21 \%$ \\
\hline
\end{tabular}

In order to explore the impact of phase structure on strain behavior at large electric field, the unipolar strain curves were measured as a function of electric fields up to $70 \mathrm{kV} / \mathrm{cm}$ at $1 \mathrm{~Hz}$, as shown in Figure 5 . At $70 \mathrm{kV} / \mathrm{cm}$, the strain of randomly oriented $88 \mathrm{NBT}$ ceramic, textured $88 \mathrm{NBT}$ ceramic, randomly oriented 90NBT ceramic, and textured 90NBT ceramic can reach $0.18 \%, 0.18 \%, 0.13 \%$ and $0.14 \%$ respectively. The $\mathrm{d}_{33}{ }^{*}$ are calculated to be $205 \mathrm{pm} / \mathrm{V}$ for the textured $90 \mathrm{NBT}$ ceramic at $70 \mathrm{kV} / \mathrm{cm}$ as compared with that of $180 \mathrm{pm} / \mathrm{V}$ for the randomly oriented $90 \mathrm{NBT}$ ceramic, i.e., the textured ceramics show an improvement about $13 \%$ in $\mathrm{d}_{33}{ }^{*}$. Compared to the $88 \mathrm{NBT}$ composition, the $\mathrm{d}_{33}{ }^{*}$ of $90 \mathrm{NBT}$ composition with rhombohedral phase has been clearly improved, while the strain level and $\mathrm{d}_{33}$ * of $88 \mathrm{NBT}$ with MPB composition are comparable in randomly oriented and textured samples, due to the extrinsic contribution, i.e., the domain wall motion, in 88NBT with coexisted rhombohedral and tetragonal phases dominates the large field piezoelectric. These results can also be confirmed by the strain hysteresis $\mathrm{H}$, where the value for rhombohedral randomly oriented $90 \mathrm{NBT}$ ceramic is about $26 \%$ at large field of $70 \mathrm{kV} / \mathrm{cm}$, lower than the MPB $88 \mathrm{NBT}$ ceramics, owing to the facilitated domain wall motion in tetragonal phase, thus higher extrinsic contribution and higher strain hysteresis. Of particular significance is that the 90NBT textured ceramic exhibits almost linear behavior even at a high electric field of $70 \mathrm{kV} / \mathrm{cm}$, with strain hysteresis being on the order of $12 \%$. In contrast to randomly oriented ceramics, the textured ceramics possess less than half of the strain hysteresis, which can be explained by the $<001>$ texturing characteristics, leading to engineered domain configuration " $4 R$ " after polarizing along $<001>$ direction, accounts for the greatly reduced strain hysteresis $[9,12,20]$.

It is concluded that different phase structures have a significant impact on the performances of textured ceramics. Based on the concept of domain engineering, significantly enhanced piezoelectric response and reduced strain hysteresis could be expected in highly $<001>$ textured ceramics with rhombohedral phase, as a result of promoted polarization rotation owing to the formation of " $4 \mathrm{R}$ " domain configuration [12,33,34], this also is confirmed by the above Rayleigh analysis. The textured 90NBT ceramic has a lower extrinsic contribution of $18 \%$ as well as lower $\mathrm{H}$ comparing to the textured $88 \mathrm{NBT}$ ceramics and the randomly oriented $90 \mathrm{NBT}$ ceramic. The greatly decreased extrinsic contribution and reduced strain hysteresis observed in textured 90NBT are inherently associated with the engineered domain configuration, domain wall density and the number of possible directions of spontaneous polarizations. Both textured ceramics were found to possess one order larger grain size when comparing to their random ceramic counterparts, as shown in Figure 1, revealing the domain size in textured ceramics is greater than that in random ceramics due to the fact that domain size is proportional to the square root of grain size $[35,36]$, leading to lower domain wall density, accounting for the smaller extrinsic contribution and strain hysteresis in the textured ceramics comparing to their randomly oriented counterparts. On the other hand, the textured 88NBT and 90NBT ceramics possess similar grain size and the same Lotgering factor, suggesting the grain size and Lotgering factor are not the dominant factors responsible for the lower extrinsic contribution of the textured 90NBT ceramic comparing to textured $88 \mathrm{NBT}$. In the $<001>$ textured $90 \mathrm{NBT}$ ceramic with the rhombohedral 
phase, all the grains are aligned along crystallographic $<001>$ direction. Analogous to $<001>$ oriented rhombohedral single crystals, the $<001>$ textured 90 NBT ceramic with rhombohedral phase will form the engineered-domain configuration after poled along $<001>$ direction (even the textured ceramic is transversely isotropic material which possesses a plane of isotropy vertical to $<001>$ direction, being different from single crystal), where the coexistence of the four degenerated domain states can stabilize the domain wall, thus less domain wall motion. The smaller extrinsic piezoelectric response and minimal strain hysteresis at a high electric field of the textured 90NBT ceramic are associated with the " $4 \mathrm{R}$ " domain engineered configuration [37].
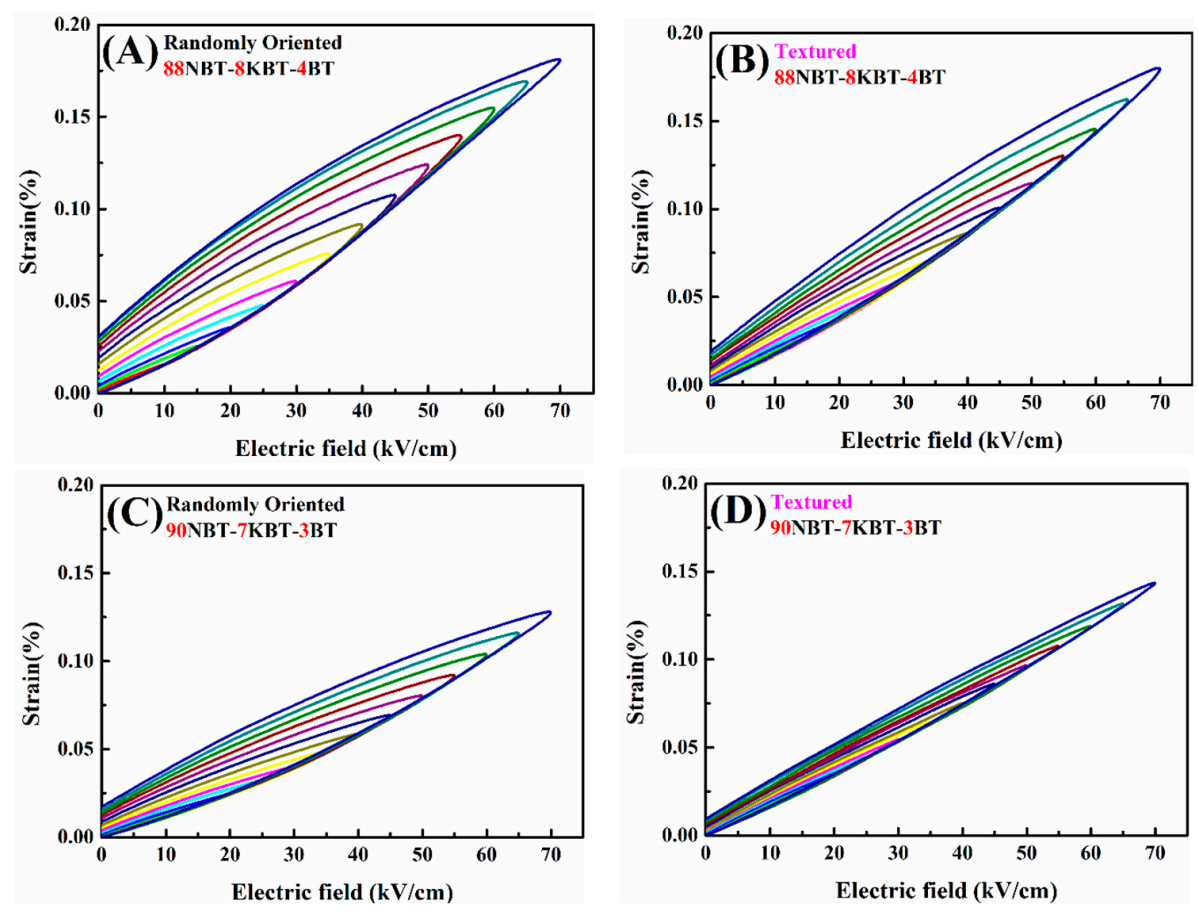

Figure 5. Strain curves for (A) randomly oriented 88NBT ceramic, (B) textured 88NBT ceramic, (C) randomly oriented $90 \mathrm{NBT}$ ceramic, and (D) textured 90NBT ceramic.

Figure $6 \mathrm{~A}-\mathrm{D}$ shows the unipolar strain curves of $88 \mathrm{NBT}$ and $90 \mathrm{NBT}$ ceramics at $40 \mathrm{kV} / \mathrm{cm}$, with temperatures ranging from room temperature (RT) to $160^{\circ} \mathrm{C}$. The corresponding strain and $\mathrm{d}_{33^{*}}$ of ceramics are plotted in Figure 6E. As shown in Figure 6A-D, the textured ceramics show relatively linear unipolar strain curves at different temperatures in contrast to the random ceramics of the same composition, which corresponds to smaller strain hysteresis. In contrast to the $88 \mathrm{NBT}$ ceramics, the 90NBT ceramics exhibit more linear unipolar strain curves, owing to the domain wall motion in the tetragonal phase. Herein as the temperature increases, the strain and $\mathrm{d}_{33}{ }^{*}$ (at $40 \mathrm{kV} / \mathrm{cm}$ ) of all ceramics both increase to maximum values at first and then decrease approaching to depolarization temperature $\mathrm{T}_{\mathrm{d}}$. This phenomenon has also been observed in NBT-BT-ST and NBT-KBT-BT ceramics [38,39]. For 88NBT randomly oriented ceramic, the unipolar strain increases gradually as the temperature rises to $100{ }^{\circ} \mathrm{C}$, which is higher than the depolarization temperature $\mathrm{T}_{\mathrm{d}}\left(\sim 80^{\circ} \mathrm{C}\right)$. The maximum unipolar strain and $\mathrm{d}_{33}{ }^{*}$ of $88 \mathrm{NBT}$ randomly oriented ceramic are $0.26 \%$ and $660 \mathrm{pm} / \mathrm{V}$, respectively, which can be achieved at a temperature of $100{ }^{\circ} \mathrm{C}$, being associated with the coexistence of ferroelectric order and ergodic relaxor phase in NBT-based ceramics. Above $100{ }^{\circ} \mathrm{C}$, the strain and $\mathrm{d}_{33^{*}}$ of $88 \mathrm{NBT}$ randomly oriented ceramic decrease. Meanwhile, it is worth noting that the $88 \mathrm{NBT}$ randomly oriented ceramic has relatively small strain hysteresis at high temperatures. In contrast, the strain and $\mathrm{d}_{33}{ }^{*}$ of $88 \mathrm{NBT}$ textured ceramic increase gradually from RT to $60^{\circ} \mathrm{C}$, followed by a sharp increase to $0.27 \%$ and 675 $\mathrm{pm} / \mathrm{V}$ at $100{ }^{\circ} \mathrm{C}$, respectively, above which, the strain and $\mathrm{d}_{33^{*}}{ }^{*}$ values of the $88 \mathrm{NBT}$ textured ceramic are reduced, showing a phenomenon similar to that of $88 \mathrm{NBT}$ randomly oriented ceramic. At RT to $140^{\circ} \mathrm{C}$, the strain and $\mathrm{d}_{33^{*}}$ of the $90 \mathrm{NBT}$ randomly oriented ceramic increase gradually, then sharply increase to 
$0.27 \%$ and $680 \mathrm{pm} / \mathrm{V}$ at $160{ }^{\circ} \mathrm{C}$, respectively. For $90 \mathrm{NBT}$ textured ceramic, the maximum unipolar strain and $\mathrm{d}_{33}{ }^{*}$ is $0.32 \%$ and $800 \mathrm{pm} / \mathrm{V}$ at $140{ }^{\circ} \mathrm{C}$, respectively. In summary, the $90 \mathrm{NBT}$ textured ceramics exhibit a linear strain linear behavior with enhanced temperature stability when the temperature below the Td in contrast to the 88 NBT textured ceramics.
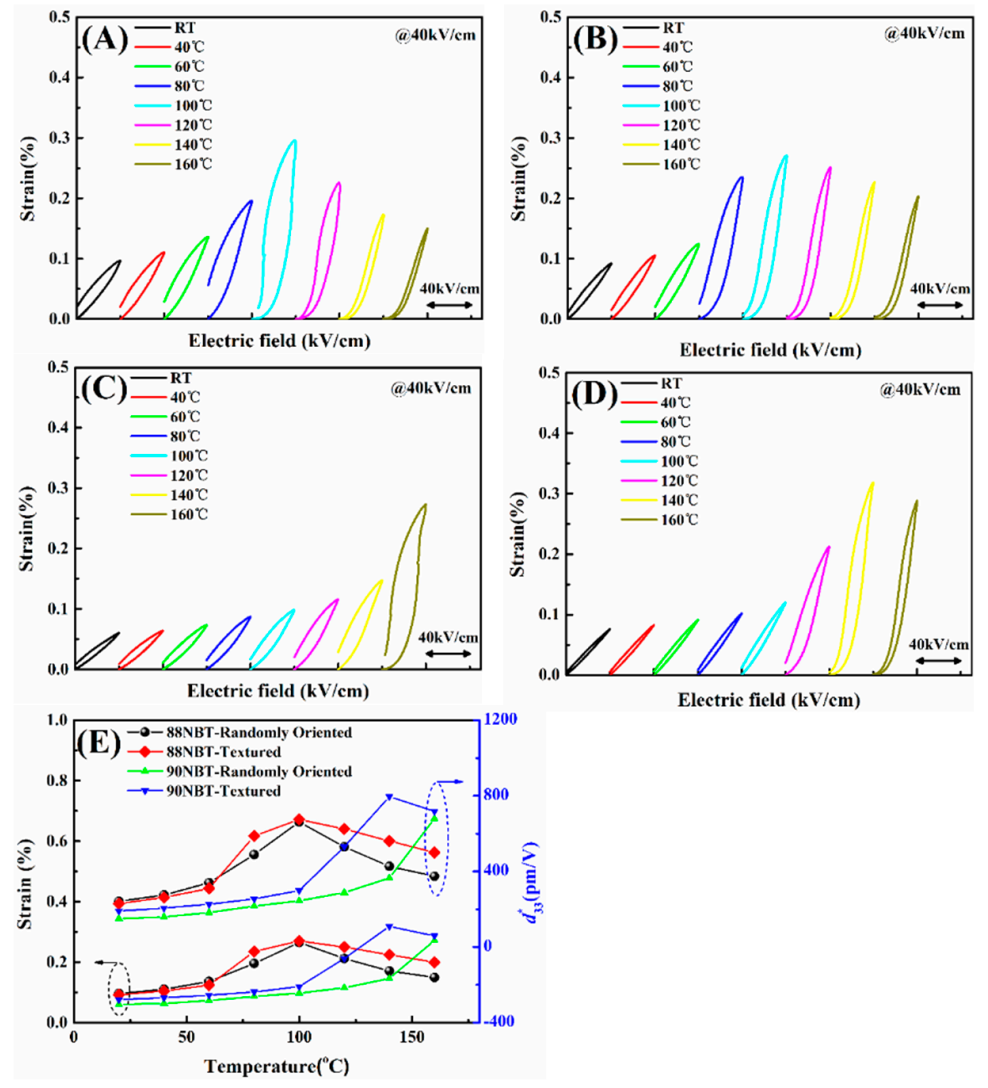

Figure 6. Temperature-dependent of unipolar strain curves of (A) 88NBT randomly oriented ceramic, (B) $88 \mathrm{NBT}$ textured ceramic, (C) 90NBT randomly oriented ceramic, and (D) 90NBT textured ceramic; (E) Strain and $\mathrm{d}_{33}{ }^{*}$ as a function of temperature for $88 \mathrm{NBT}$ and $90 \mathrm{NBT}$ ceramics at $40 \mathrm{kV} / \mathrm{cm}$.

\section{Conclusions}

Highly <001>-textured 88NBT (MPB) and 90NBT (rhombohedral phase) ceramics with Lotgering factor f $96 \%$ were prepared via the TGG method. The piezoelectric coefficients of $88 \mathrm{NBT}$ textured and 90 NBT textured ceramics are increased by $20 \%$ and $60 \%$, respectively, compared to their randomly oriented ones. Additionally, the $\mathrm{d}_{33}{ }^{*}$ of $90 \mathrm{NBT}$ textured ceramic possess $13 \%$ enhancement compared to its randomly oriented counterpart; however, the $\mathrm{d}_{33}{ }^{*}$ of textured $88 \mathrm{NBT}$ ceramic maintains a similar value. These results demonstrate that the different phase structures have a significant impact on the properties of textured ceramics. Based on the Rayleigh analysis and strain behavior, the enhancement of piezoelectric properties and minimal strain hysteresis of 90NBT textured ceramics can be explained by the increased rhombohedral phase and " $4 \mathrm{R}$ " domain engineered configuration comparing to $88 \mathrm{NBT}$ textured ceramics.

Author Contributions: Material fabrication and property characterization, N.D. and X.G.; writing一original draft, N.D. and X.G.; writing-review and editing, N.D., X.G., F.X., Q.G., H.H., H.L. and S.Z. All authors have read and agreed to the published version of the manuscript.

Funding: This work was supported by NSFC-Guangdong Joint Funds of the Natural Science Foundation of China (No.U1601209), Major Program of the Natural Science Foundation of China (51790490) and the Technical Innovation Program of Hubei Province (Grant No. 2017AHB055).

Conflicts of Interest: The authors declare no conflict of interest. 


\section{References}

1. Smolensky, G. New ferroelectrics of complex composition IV. Sov. Phys. Solid State. 1961, 2, $2651-2654$.

2. Li, Y.; Chen, W.; Zhou, J.; Xu, Q.; Sun, H.; Liao, M. Dielectric and ferroelectric properties of lead-free $\mathrm{Na}_{0.5} \mathrm{Bi}_{0.5} \mathrm{TiO}_{3}-\mathrm{K}_{0.5} \mathrm{Bi}_{0.5} \mathrm{TiO}_{3}$ ferroelectric ceramics. Ceram. Int. 2005, 31, 139-142. [CrossRef]

3. Chen, M.; Xu, Q.; Kim, B.H.; Ahn, B.K.; Ko, J.H.; Kang, W.J.; Nam, O.J. Structure and electrical properties of $\left(\mathrm{Na}_{0.5} \mathrm{Bi}_{0.5}\right)_{1-\mathrm{x}} \mathrm{Ba}_{\mathrm{x}} \mathrm{TiO}_{3}$ piezoelectric ceramics. J. Eur. Ceram. Soc. 2008, 28, 843-849. [CrossRef]

4. Swain, S.; Kumar, P. Dielectric, ferroelectric and bipolar electric field induced strain properties of MPB composition of NBT-xKNN system. J. Electroceram. 2013, 32, 102-107. [CrossRef]

5. Zhang, S.; Shrout, T.R.; Nagata, H.; Hiruma, Y.; Takenaka, T. Piezoelectric properties in $\left(\mathrm{K}_{0.5} \mathrm{Bi}_{0.5}\right) \mathrm{TiO}_{3}-\left(\mathrm{Na}_{0.5} \mathrm{Bi}_{0.5}\right) \mathrm{TiO}_{3}-\mathrm{BaTiO}_{3}$ lead-free ceramics. IEEE Trans. Ultrason. Ferroelectr. Freq. Control. 2007, 54, 910-917. [CrossRef]

6. Zhang, L.; Pu, X.; Chen, M.; Bai, S.; Pu, Y. Influence of $\mathrm{BaSnO}_{3}$ additive on the energy storage properties of $\mathrm{Na}_{0.5} \mathrm{Bi}_{0.5} \mathrm{TiO}_{3}$-based relaxor ferroelectrics. J. Eur. Ceram. Soc. 2018, 38, 2304-2311. [CrossRef]

7. Lou, G.; Yin, Q.; Duan, A.; Cao, D.; Yin, X. Structure, dielectric properties and impedance analysis of lead-free (1-x) $\mathrm{Na}_{0.5} \mathrm{Bi}_{0.5} \mathrm{TiO}_{3}-x \mathrm{SrTiO}_{3}$ ceramics. J. Mater. Sci. Mater. Electron. 2018, 29, 6283-6288. [CrossRef]

8. Liu, X.; Li, F.; Zhai, J.; Shen, B.; Li, P.; Liu, B. Composition-induced structural transitions and enhanced strain response in nonstoichiometric NBT-based ceramics. J. Am. Ceram. Soc. 2017, 100, 3636-3645. [CrossRef]

9. Moriana, A.D.; Zhang, S. Lead-free textured piezoceramics using tape casting: A review. J. Materiomics. 2018, 4, 277-303. [CrossRef]

10. Messing, G.L.; Trolier-McKinstry, S.; Sabolsky, E.; Duran, C.; Kwon, S.; Brahmaroutu, B.; Park, P.; Yilmaz, H.; Rehrig, P.; Eitel, K. Templated grain growth of textured piezoelectric ceramics. Crit. Rev. Solid State Mater. Sci. 2004, 29, 45-96. [CrossRef]

11. Seabaugh, M.M.; Cheney, G.L.; Hasinska, K.; Azad, A.-M.; Sabolsky, E.M.; Swartz, S.L.; Dawson, W.J. Development of a templated grain growth system for texturing piezoelectric ceramics. J. Intell. Mater. Syst. Struct. 2004, 15, 209-214. [CrossRef]

12. Zhang, S.; Li, F. High performance ferroelectric relaxor- $\mathrm{PbTiO}_{3}$ single crystals: Status and perspective. J. Appl. Phys. 2012, 111, 031301. [CrossRef]

13. Zhang, S.; Sherlock, N.P.; Meyer, R.J., Jr.; Shrout, T.R. Crystallographic dependence of loss in domain engineered relaxor-PT single crystals. Appl. Phys. Lett. 2009, 94, 162906. [CrossRef] [PubMed]

14. Davis, M.; Damjanovic, D.; Hayem, D.; Setter, N. Domain engineering of the transverse piezoelectric coefficient in perovskite ferroelectrics. J. Appl. Phys. 2005, 98, 014102. [CrossRef]

15. Bell, A.J. Phenomenologically derived electric field-temperature phase diagrams and piezoelectric coefficients for single crystal barium titanate under fields along different axes. J. Appl. Phys. 2001, 89, 3907-3914. [CrossRef]

16. Li, P.; Zhai, J.; Shen, B.; Zhang, S.; Li, X.; Zhu, F.; Zhang, X. Ultrahigh piezoelectric properties in textured (K, $\mathrm{Na}) \mathrm{NbO}_{3}$-based lead-free ceramics. Adv. Mater. 2018, 30, 1705171. [CrossRef]

17. Li, P.; Liu, B.; Shen, B.; Zhai, J.; Zhang, Y.; Li, F.; Liu, X. Mechanism of significantly enhanced piezoelectric performance and stability in textured potassium-sodium niobate piezoelectric ceramics. J. Eur. Ceram. Soc. 2018, 38, 75-83. [CrossRef]

18. Qin, Y.; Zhang, J.; Yao, W.; Lu, C.; Zhang, S. Domain configuration and thermal stability of $\left(\mathrm{K}_{0.48} \mathrm{Na}_{0.52)}\left(\mathrm{Nb}_{0.96} \mathrm{Sb}_{0.04}\right) \mathrm{O}_{3}-\mathrm{Bi}_{0.50}\left(\mathrm{Na}_{0.82} \mathrm{~K}_{0.18}\right)_{0.50} \mathrm{ZrO}_{3}\right.$ Piezoceramics with High $\mathrm{d}_{33}$ coefficient. ACS Appl. Mater. Interfaces 2016, 8, 7257-7265. [CrossRef]

19. Zhang, H.; Xu, P.; Patterson, E.; Zang, J.; Jiang, S.; Rödel, J. Preparation and enhanced electrical properties of grain-oriented $\left(\mathrm{Bi}_{1 / 2} \mathrm{Na}_{1 / 2}\right) \mathrm{TiO}_{3}$-based lead-free incipient piezoceramics. J. Eur. Ceram. Soc. 2015, 35, 2501-2512. [CrossRef]

20. Liu, Y.; Chang, Y.; Li, F.; Yang, B.; Sun, Y.; Wu, J.; Zhang, S.; Wang, R.; Cao, W. Exceptionally high piezoelectric coefficient and low strain hysteresis in grain-oriented $(\mathrm{Ba}, \mathrm{Ca})(\mathrm{Ti}, \mathrm{Zr}) \mathrm{O}_{3}$ through integrating crystallographic texture and domain engineering. ACS Appl. Mater. Interfaces 2017, 9, 29863-29871. [CrossRef]

21. Hu, G.; Xu, B.; Yan, X.; Li, J.; Gao, F.; Liu, Z.; Zhang, Y.; Sun, H. Fabrication and electrical properties of textured $\mathrm{Ba}\left(\mathrm{Zr}_{0.2} \mathrm{Ti}_{0.8}\right) \mathrm{O}_{3}-\left(\mathrm{Ba}_{0.7} \mathrm{Ca}_{0.3}\right) \mathrm{TiO}_{3}$ ceramics using plate-like $\mathrm{BaTiO}_{3}$ particles as templates. J. Mater. Sci. Mater. Electron. 2014, 25, 1817-1827. [CrossRef] 
22. Maurya, D.; Zhou, Y.; Yan, Y.; Priya, S. Synthesis mechanism of grain-oriented lead-free piezoelectric $\mathrm{Na}_{0.5} \mathrm{Bi}_{0.5} \mathrm{TiO}_{3}-\mathrm{BaTiO}_{3}$ ceramics with giant piezoelectric response. J. Mater. Chem. C 2013, 1, $2102-2111$. [CrossRef]

23. Bai, W.; Chen, D.; Zheng, P.; Xi, J.; Zhou, Y.; Shen, B.; Zhai, J.; Ji, Z. $\mathrm{NaNbO}_{3}$ templates-induced phase evolution and enhancement of electromechanical properties in $<001>$ grain oriented lead-free BNT-based piezoelectric materials. J. Eur. Ceram. Soc. 2017, 37, 2591-2604. [CrossRef]

24. Hao, J.; Ye, C.; Shen, B.; Zhai, J. Enhanced electrostricitive properties and thermal endurance of textured $\left(\mathrm{Bi}_{0.5} \mathrm{Na}_{0.5}\right) \mathrm{TiO}_{3}-\mathrm{BaTiO}_{3}-\left(\mathrm{K}_{0.5} \mathrm{Na}_{0.5}\right) \mathrm{NbO}_{3}$ ceramics. J. Appl. Phys. 2013, 114, 054101. [CrossRef]

25. Li, L.; Zhang, Y.; Bai, W.; Shen, B.; Zhai, J.; Chen, H. Synthesis of high aspect ratio (K, Na) $\mathrm{NbO}_{3}$ plate-like particles and study on the synthesis mechanism. Dalton Trans. 2015, 44, 11621-11625. [CrossRef] [PubMed]

26. Jiang, C.; Zhou, X.; Zhou, K.; Chen, C.; Luo, H.; Yuan, X.; Zhang, D. Grain oriented $\mathrm{Na}_{0.5} \mathrm{Bi}_{0.5} \mathrm{TiO}_{3}-\mathrm{BaTiO}_{3}$ ceramics with giant strain response derived from single-crystalline $\mathrm{Na}_{0.5} \mathrm{Bi}_{0.5} \mathrm{TiO}_{3}-\mathrm{BaTiO}_{3}$ templates. J. Eur. Ceram. Soc. 2016, 36, 1377-1383. [CrossRef]

27. Lotgering, F.K. Topotactical reactions with ferrimagnetic oxides having hexagonal crystal structures-I. J. Inorg. Nucl. Chem. 1959, 9, 113-123. [CrossRef]

28. Liu, G.; Jiang, W.; Zhang, L.; Cai, J.; Wang, Z.; Liu, K.; Liu, X.; Chen, Y.; Liu, H.; Yan, Y. Effects of sintering temperature and KBT content on microstructure and electrical properties of $\left(\mathrm{Bi}_{0.5} \mathrm{Na}_{0.5}\right) \mathrm{TiO}_{3}-\mathrm{BaTiO}_{3}-\left(\mathrm{Bi}_{0.5} \mathrm{~K}_{0.5}\right) \mathrm{TiO}_{3} \mathrm{~Pb}$-free ceramics. Ceram. Int. 2018, 44, 9303-9311. [CrossRef]

29. Damjanovic, D.; Demartin, M. Contribution of the irreversible displacement of domain walls to the piezoelectric effect in barium titanate and lead zirconate titanate ceramics. J. Phys. Condens Matter. 1997, 9, 4943-4953. [CrossRef]

30. Davis, M.; Damjanovic, D.; Setter, N. Temperature dependence of the direct piezoelectric effect in relaxor-ferroelectric single crystals: Intrinsic and extrinsic contributions. J. Appl Phys. 2006, 100, 084103. [CrossRef]

31. Wang, Y.U. Three intrinsic relationships of lattice parameters between intermediate monoclinic $\mathrm{M}_{\mathrm{C}}$ and tetragonal phases in ferroelectric $\mathrm{Pb}\left[\left(\mathrm{Mg}_{1 / 3} \mathrm{Nb}_{2 / 3}\right)_{1-\mathrm{x}} \mathrm{Ti}_{\mathrm{x}}\right] \mathrm{O}_{3}$ and $\mathrm{Pb}\left[\left(\mathrm{Zn}_{1 / 3} \mathrm{Nb}_{2 / 3}\right)_{1-\mathrm{x}} \mathrm{Ti}_{\mathrm{x}}\right] \mathrm{O}_{3}$ near morphotropic phase boundaries. Phys Rev. B Condens. Matter Mater. Phys. 2006, 73, 014113. [CrossRef]

32. Jin, Y.; Wang, Y.U.; Khachaturyan, A.G.; Li, J.; Viehland, D. Conformal miniaturization of domains with low domain-wall energy: Monoclinic ferroelectric states near the morphotropic phase boundaries. Phys. Rev. Lett. 2003, 91, 197601. [CrossRef] [PubMed]

33. Li, F.; Zhang, S.; Xu, Z.; Chen, L.Q. The contributions of polar nanoregions to the dielectric and piezoelectric responses in domain-engineered relaxor-PbTiO 3 crystals. Adv. Funct. Mater. 2017, 27, 1700310. [CrossRef]

34. Sun, E.; Cao, W. Relaxor-based ferroelectric single crystals: Growth, domain engineering, characterization and applications. Prog. Mater. Sci. 2014, 65, 124-210. [CrossRef]

35. Cao, W.; Randall, C. Grain size and domain size relations in bulk ceramic ferroelectric materials. J. Phys. Chem. Solids 1996, 57, 1499-1505. [CrossRef]

36. Hoshina, T.; Kigoshi, Y.; Hatta, S.; Teranishi, T.; Takeda, H.; Tsurumi, T. Size effect and domain-wall contribution of Barium titanate ceramics. Ferroelectrics 2010, 402, 29-36. [CrossRef]

37. Li, F.; Zhang, S.; Xu, Z.; Wei, X.; Luo, J.; Shrout, T.R. Composition and phase dependence of the intrinsic and extrinsic piezoelectric activity of domain engineered (1-x) $\mathrm{Pb}\left(\mathrm{Mg}_{1 / 3} \mathrm{Nb}_{2 / 3}\right) \mathrm{O}_{3}-\mathrm{xPbTiO}_{3}$ crystals. J. Appl. Phys. 2010, 108, 034106. [CrossRef]

38. Zhang, S.-T.; Yang, B.; Cao, W. The temperature-dependent electrical properties of $\mathrm{Bi}_{0.5} \mathrm{Na}_{0.5} \mathrm{TiO}_{3}-\mathrm{BaTiO}_{3}-\mathrm{Bi}_{0.5} \mathrm{~K}_{0.5} \mathrm{TiO}_{3}$ near the morphotropic phase boundary. Acta Mater. 2012, 60, 469-475. [CrossRef]

39. Wang, F.; Xu, M.; Tang, Y.; Wang, T.; Shi, W.; Leung, C.M. Large strain response in the ternary $\mathrm{Bi}_{0.5} \mathrm{Na}_{0.5} \mathrm{TiO}_{3}-\mathrm{BaTiO}_{3}-\mathrm{SrTiO}_{3}$ solid solutions. J. Am. Ceram. Soc. 2012, 95, 1955-1959. [CrossRef]

(C) 2020 by the authors. Licensee MDPI, Basel, Switzerland. This article is an open access article distributed under the terms and conditions of the Creative Commons Attribution (CC BY) license (http://creativecommons.org/licenses/by/4.0/). 